\title{
Annual Report 2016
}

Human Resources for Education, Research and Service

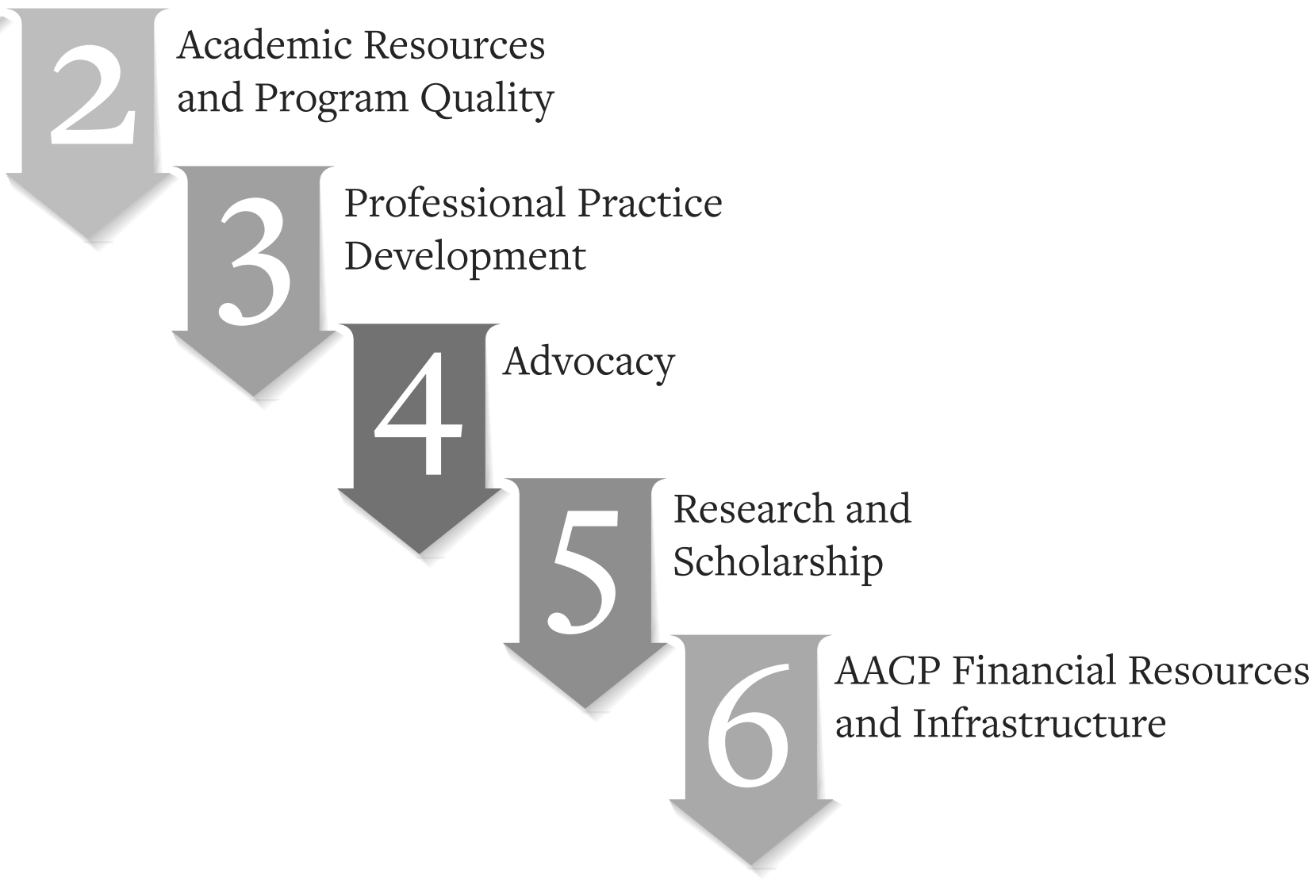

\section{American Association of Colleges of Pharmacy}

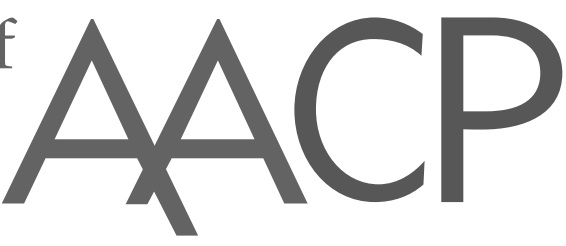




\section{Message from the President and the Executive Vice President \& CEO}

Dear Colleagues:

The 2015-16 AACP Annual Report follows the six critical issues that have directed our work since the 2010 House of Delegates approved a new strategic plan. These issues remain vital to our day-to-day work as evidenced by our accomplishments for the past year. Important programs such as AACP Institutes, the Academic Leadership Fellows Program, which completes the 12th cohort in July, and newer programs like the Academic Research Fellows Program, now in its 3 rd year, are cornerstones of our service to our members.

There are a number of new or renewed programs and services described in this report. The rebuilding and release of a completely new Assessment and Accreditation Management System, to allow schools to complete self-studies for ACPE's Standards 2016, is an example of a renewed program. A new AAMS was necessary to keep pace with the needs of members with comprehensive accreditation reviews beginning this Fall. Many new features and flexibility for users appear in AAMS 2.0. The completion of six "quests" in our online educational game for interprofessional learning is another.

The 2015-16 AACP Strategic Planning Committee embarked on the development of new plan; they were challenged by their Board of Directors colleagues to create one that is bold and visionary! Delegates to the July 2016 House of Delegates will be asked to review and approve just such a plan that includes four strategic priority areas and four supporting priority areas. The Strategic Priorities include:

- Increasing the applicant pipeline to our colleges and schools;

- Embarking on a collaborative campaign to communicate to key audiences about exciting roles and careers for our graduates;

- Accelerating transformation in pharmacy education and practice;

- Expanding graduate education and research activities; and,

The Presidential theme for this year is "Capitalizing on Foundations in Citizenship". In my remarks in July 2015 I emphasized the important and collaborative role in which AACP engages you, our members, in advancing the academy in strategic directions. The work of our standing and special committees, councils, sections, and special interest groups exemplifies this collaboration perfectly. And our Board of Directors and staff provide the strategic direction and hands on work to bring strategy to fruition in meaningfully important ways. Our thanks to you all for your contributions.

Sincerely,

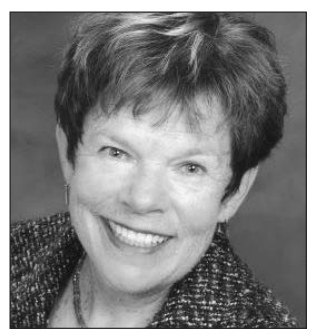

Cynthia J. Boyle,

Pharm.D., FAPhA

President, AACP

Professor and Chair of the

Department of Pharmacy

Practice and Administration

University of Maryland Eastern

Shore School of Pharmacy and

Health Professions

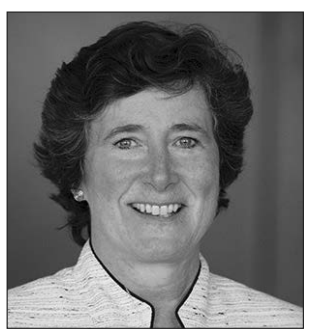

Lucinda L. Maine, Ph.D., R.Ph.

Executive Vice President and CEO, AACP 


\section{Critical Issue 1 \\ Human Resources for Education, Research and Service}

How does AACP assist members in attracting, motivating, developing and retaining the highest quality and most diverse faculty, students, administrators and professional staff?

Weademic Leadership Fellows Program

\section{ALFP (Academic Leadership Fellows Program)}

The continuously popular ALFP Program completed recruitment of the 30 Fellows to participate in the 13th cohort for the 2016-2017 year. Each year more applications are received than can be accommodated, so in order to maintain quality and personal/professional development, the number of Fellow's per cohort is limited to this number. Each cohort benefits from the intense efforts of the ALFP advisory committee, dedicated pharmacy leaders and AACP staff, who continuously improve and refine the leadership-development programming provided to these future leaders.

\section{Walmart Scholars Update}

The AACP Walmart Scholars Program continues to focus on developing future faculty. The program brings students to the AACP Annual Meeting to strengthen their commitment to an academic pharmacy career.

The number of scholarships continued at 85 in 2015. (Walmart supports the majority of the scholarships, and AACP provides support for 10 scholarships) This brings the total number of recipients during the program's eleven-year history to close to 700 .

\section{PharmCAS Update}

The Pharmacy College Application Service (PharmCAS) completed its thirteenth cycle this year with 124 participating PharmD programs and 9 graduate programs. In the 2015-16 admissions cycle, PharmCAS experienced a $1.67 \%$ decrease in the number of applicants and a 5.4\% decrease in the number of applications submitted, with an average of 4.14 applications per applicant, which is a $3.7 \%$ decrease from the previous year. The accompanying tables display additional data. Promoting student diversity and access to pharmacy education, AACP continued the PharmCAS fee waiver program for financially disadvantaged applicants.

Applicants

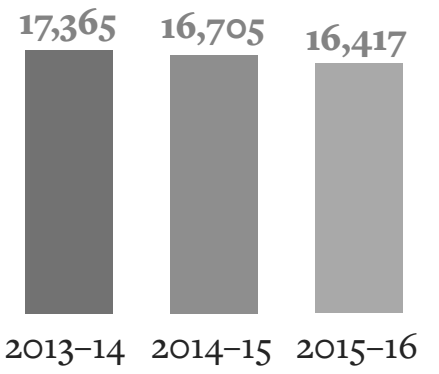

Number 116 of Schools
119

124
Applications

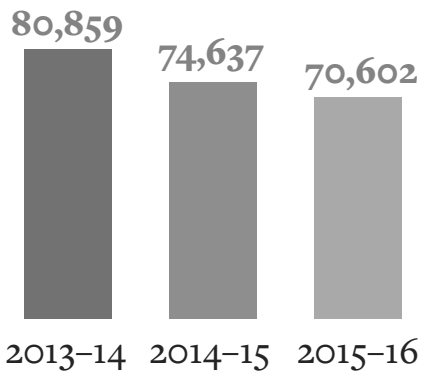

$\begin{array}{cccc}\begin{array}{c}\text { Number } \\ \text { of Schools }\end{array} & 116 & 119 & 124\end{array}$




\section{Critical Issue 2 Academic Resources and Program Quality}

How do we facilitate members having the necessary resources to advance their institutional missions and achieve the highest quality programs that exceed the standards of accreditation bodies?

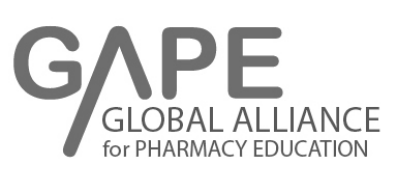

\section{Global Pharmacy Education}

AACP maintains active membership in the International Pharmacy Federation known as FIP and serves on the planning committee for a global conference on pharmacy education to be held in Nanjing, China in November 2016. The conference aims to bring approximately 300 individuals together to establish a common vision for strengthening pharmacists' education across the world to insure that quality medications are available and used safely in every country. The conferees will establish a set of global development goals related to pharmacy education and practice during the conference.

\section{Award for Excellence in Assessment}

The Award for Excellence in Assessment recognizes outstanding Doctor of Pharmacy assessment programs for developing and applying evidence of outcomes as part of the ongoing evaluation and improvement of pharmacy professional education. The 2016 award recipients are:

PIE-RECAP: A Structured Reflective Journal Writing Model and Rubric to Guide Development of Self-Awareness and Actionable Plans for Positive Change Pacific University Oregon School of Pharmacy

David G. Fuentes, Pharm.D., BCPP, CGP

Assistant Dean for Academics and Assessment and Associate Professor

Jeremy A. Hughes, Pharm.D.

Assistant Dean for Student Affairs and Assistant Professor

Anita J. Cleven, Pharm.D.

Director of Experiential Education and Assistant Professor

Jackson Ross, M.A.

Coordinator for Student and Experiential Affairs

Fawzy Elbarbry, Ph.D., RPh

Associate Professor

Ian C. Doyle, Pharm.D., BCPS

Assistant Dean for Pharmacy Practice and Assistant Professor

Mark A. Della Paolera, Pharm.D., BCACP

Associate Professor

Brendan Stamper, Ph.D.

Assistant Professor

Kelli Cadelinia, Pharm.D., Candidate, 2016

Evaluation of a Systematic Curriculum Review Process and Impact on the Pharmacy Curriculum.

Northeastern University School of Pharmacy

Jennifer Kirwin, Pharm.D., BCPS

Margarita DiVall, Pharm.D., MEd, BCPS

Danielle Miller, Pharm.D. 
Programmatic Evaluation and Quality Improvement: Designing and Implementing a Systematic Process for Assessing and Improving Faculty Peer Observations University of Illinois at Chicago College of Pharmacy

Kate Aument

Rosalyn P. Vellurattil, Pharm.D.

\section{Innovations in Teaching Competition}

Each year, the Innovations in Teaching Competition acknowledges notable teaching and learning strategies and assessment methods.

2016 Innovations in Teaching Competition Winners:

Implementation of a Novel Intersession Course during the $\mathrm{P}_{4}$ Year Joseph J. Saseen, Allison B. Blackmer, Megan Thompson, Jason Brunner University of Colorado Skaggs School of Pharmacy and Pharmaceutical Sciences

A Novel Use of Photovoice Methodology in a Leadership APPE and Pharmacy Leadership Elective

Jane E. Wilson, Michael J Smith, Tammy L. Lambert, David L. George

University of Oklahoma College of Pharmacy

2016 Innovations in Teaching Competition Honorable Mention:

Creating an Open-Access, Interprofessional Multimedia Healthcare Journal Driven by Students at Butler University: BU Well

Erin L Albert and Mary Graham

Butler University

Creative Thinking, Innovation and TED Talks: An Elective Course

Jeff Cain

University of Kentucky

Developing Professionalism: an assessment-for-learning approach

Michael J Peeters

University of Toledo College of Pharmacy and Pharmaceutical Sciences

Educating Pharmacists in Quality (EPIQ)

Donna West-Strum (University of Mississippi), Terri Warholak (University of Arizona), Ana Hincapie (University of Arizona), Vibhuti Arya (St. John's University), David Holdford (Virginia Commonwealth University), Sam Stolpe (PQA), Melissa Nelson (University of Arizona), Patrick Campbell (University of Arizona), Maria Scarlotos (PQA), Hannah Fish (PQA)

\section{AACP Institute}

The AACP 2015 Fall Institute was an encore of the popular 2015 Spring Institute dealing with the new ACPE Standards 2016, which focused particularly on Interprofessional, Experiential, and Co-curricular education. The new standards have been implemented and thus are a concern of all colleges and schools of pharmacy. The Spring 2016 Institute focused on Experiential Education. One hundred ninety-seven participants from 45 colleges and schools focused on assessment, quality assurance and interprofessional education during the two and one-half day event. An encore has already been planned for October, 2016, as a result of the extreme interest in the topic. 
The joint AACP-AFPC Annual Meeting at Washington National Harbor drew a record 2,337 attendees and featured more than 200 sessions.

Members had access to quality programs and sessions:

- The 2015 Teachers Seminar provided insight regarding the value of selfawareness in the journey of student pharmacists through didactic, experiential, and extra-curricular training to optimize the knowledge, skills, and attitudes of graduates entering pharmacy practice. Participants explored strategies that assess the achievement of the CAPE 2013 outcomes of self- awareness related to professionalism and collaboration; to communication and the role of the pharmacist educator; to promoting leadership; and to promoting problem solving.

- Opening General Session: SuperBetter: Unlocking the Psychology of Games as a Pathway to Better Health. AACP President Patricia Chase and AFPC President Kerry Mansell shared important updates on the work of their respective associations. Jane McGonigal described how serious games are transforming teaching and learning for new and not so new generations of learners. She explained how we can cultivate new powers of recovery and resilience in everyday life, simply by adopting a gameful mindset. Being gameful means bringing the same psychological strengths we naturally display when we play games-such as optimism, creativity, courage and determination - to real-world situations.

- Science Plenary: From Hypothesis to Health: Understanding the Power of the Patient Partnership. Over several decades, the role of patients and patient advocacy groups has changed dramatically. Today, these participants are technologically retooled, armed and ready with an increasingly sophisticated mindset to execute a different kind of partnership with science and the healthcare enterprise. Researchers and clinicians alike must comprehend and embrace the significance of patient and public participation in the full range of research efforts, from hypothesis to health. A distinguished panel of researchers and advocates discussed how the full engagement of the public in research on health is transforming this element of our mission. Debra R. Lappin, J.D., Principal, Faegre BD Consulting moderated the panel which included Theresa M. Mullin, Ph.D., Director, FDA Office of Strategic Programs, Eleanor M. Perfetto, Ph.D., Professor, Pharmaceutical Health Services Research, University of Maryland School of Pharmacy, and Sharon F. Terry, M.A., President, Genetic Alliance.

- Tuesday General Session: Holding Fast to Dreams. Dr. Freeman A. Hrabowski III is nationally recognized for his teaching and academic leadership. He has served as president of The University of Maryland, Baltimore County since 1992, where he has concentrated on the development of programs to reach and support under-advantaged learning populations in beginning and completing their education. In 2012, President Obama named him chair of the President's Advisory Commission on Educational Excellence for African Americans. Hrabowski's presentation, based on his book Holding Fast to Dreams, showcased his efforts and provided guidance in both developing and sustaining programs for under-advantaged learners. The 2015 Rufus A. Lyman Award and Student Community Engaged Service Awards were presented. The Capitol Steps entertained with musical satire befitting our time near the nation's capital. 


\section{Interim Meeting}

The 2016 Interim Meeting, Innovation and Effective Leadership, highlighted strategies to avoid resistance and lead change through mentorship, technology and much more. Each day focused on a different aspect of institutional leadership-leadership outside the institution, leadership within the institution, and also honing skills for institutional improvement. A record 399 members, including deans, department chairs, and aspiring leaders in the Academy came together in Tampa, FL. Highlights from the meeting include:

- Synergistic Relationships among Health Professions in Education and Practice

- Edmund Funai and Elizabeth Byerley shared their thoughts on (1) innovations and collaborations with schools of pharmacy that they have participated in or are aware of, (2) what they perceived as the benefit or limitations of those interactions, (3) their suggestions on how to establish those types of innovations on other campuses and what is the value added to their programs/schools and (4) also sharing their thoughts on IPE and IPE team based care.

- The 2015-2016 ALFP Fellows presented debates on leadership topics related to speakers' topics.

- Leading Change Without the Resistance: An Introduction To The Signature Style ${ }^{\mathrm{TM}}$

- Doug Krug gave an energetic presentation of The Signature Style ${ }^{\mathrm{TM}}$.

- The Signature Style ${ }^{\mathrm{TM}}$ is a breakthrough methodology that generates and sustains the shifts in thinking essential for more people making more of the right decisions more often, no matter what situation is faced. It is built on the belief that implementing successful change/improvement would be much easier if we didn't cause so much resistance to begin with.

- Leading to Wellbeing

- Nance Lucas led an interactive session that explored the intersections of leadership and well-being, bridging science with evidence-based practices that yield higher optional human and organizational flourishing, improve productivity, inspire greater meaning and purpose in life, and increase engagement.

OFFICE OF

INSTITUTIONAL RESEARCH \& EFFECTIVENESS

\section{Institutional Research \& Effectiveness}

To accommodate Standards 2016, the Institutional Research and Assessment Committee revised the four curriculum quality surveys (Graduating Student, Faculty, Alumni, and Preceptor) in 2015. The first administration of the revised surveys began in spring 2016.

To enhance member accessibility to our data, AACP staff are:

- Utilizing Tableau, a data visualization software, to re-design the trend data files on the AACP website;

- Publishing a quarterly Institutional Research newsletter to succinctly communicate updates and reports regarding AACP surveys and the AAMS

- Designing infographics that communicate patterns and stories about pharmacy education. 


\section{Assessment and Accreditation Management System (AAMS)}

AACP and the Accreditation Council for Pharmacy Education (ACPE) launched the new AAMS for Standards 2016 in December 2015. The system includes new streamlined features, such as:

- Enhanced document management with tagging and URL uploads

- Text versioning with time stamps and name of user

- Simplified user roles and permissions

- Enhanced data views

- Additional benchmarking reports

AACP has created a series of training videos and a FAQ page to help users get started in the new system.

\section{Webinar programming}

AACP's Webinar programming provides a valuable tool for member engagement. Each Section/SIG is allowed three programmatic Webinars and three operational Webinars (business meetings). AACP Webinar programming has grown considerably over the past several years, and has become a popular way for members to share knowledge, experiences, and best practices with each other.

Recent Webinar highlights include:

- AACP hosted 26 programmatic Webinars this year from Sections, SIGs, and the pipeline development series. Some of the topics have included Pharmacy Curriculum Outcomes Assessment (PCOA), Incorporating Electronic Health Records into the Classroom, Gaming in Pharmacy Education, and much more.

- AACP hosted 8 operational Webinars this year, including Section/SIG business meetings, focus groups, and HOD orientations.

- AACP now has over 70 recorded Webinars on our Web site

AACP continues to expand the use of the Webinar platform to meet the professional development needs of the membership. In the past several years, AACP has significantly increased the number of programmatic Webinars offered to members.

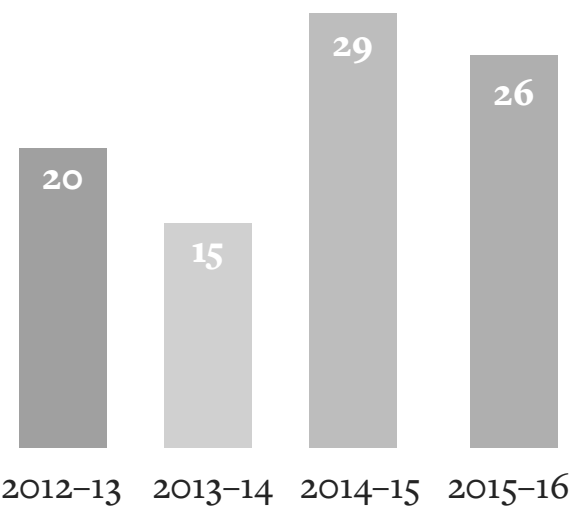


AACP began development of the first online, multiplayer game for interprofessional learning in 2014. As of June 2016 six different games, or quests, and many mini-games had been built and tested. Each quest presents a scenario appropriate to various disciplines across the health professions and includes topics such as substance abuse, infectious disease, genetics and other public health-related issues.

Several investigators have embarked upon research using Mimycx, including:

- Chapman College of Pharmacy: Are you game for fun, interactive learning? Lam J, Goad J, Sparks L, Chapman University; Odessky L AACP Annual Meeting, Pharmacy Education 2016; Anaheim, CA, July 2016

- AACP: Serious Video Games as interprofessional education collaboration and teamwork activity.

Larisa Odessky, PharmD., Academic Fellow at American Association of Colleges of Pharmacy (in progress)

- University of Wisconsin New Investigator Award: Joseph A. Zorek, Evaluating the Utility of Mimycx to Advance Interprofessional Experiential Education (in progress)

\section{Continuing Education/Continuing Professional Development}

Last year we reported AACP received approval from ACPE to be a CPE-Provider and offer continuing education credits directly to members. The February, 2016 Interim Meeting and ALFP Session III were AACP's first opportunity to provide this service to members. A total of 1516.25 continuing education hours were awarded to individuals participating in these events. These numbers will multiply as AACP provides additional outlets to provide continuing education training at Annual Meetings, Institutes, and educational webinars.

\section{Section and SIG CAPE Papers}

The goal of the Section and SIG CAPE Papers process was to have the different content areas represented create a guidance document that describes:

1. How their respective subject is reflected in the CAPE 2013 Educational Outcomes, how this subject matter will be achieved pedagogically, and finally, how it will be assessed.

2. Suggestions on how colleagues in a given discipline could use CAPE 2013 in the design, delivery and assessment of their courses or professional programs.

Five papers are now available on the AACP Web site from the Assessment, Curriculum, Global, Pharmacogenomics and Leadership Development SIGs 


\section{Critical Issue 3 Professional Practice Development}

3

How do we help fully integrate pharmacists into the rapidly changing health care environment and prepare our faculty and students to understand and fulfill those roles?

\section{Interprofessional Education (IPEC)}

The Interprofessional Education Collaborative (IPEC) facilitates the growth and enhancement of interdisciplinary learning among the health science colleges and schools. AACP is proud to be one of the founding organizations and pleased to see the additional health science disciplines joining the planning process. During IPEC Institutes, attendees discuss the fundamentals of interprofessional education, listen to practice experts, participate in team-based activities and identify faculty development opportunities which will improve public health. IPEC Institutes are held in Herndon, VA, convenient to several modes of transportation

October 2015 IPEC Institute: Interprofessional Education:

Building a Framework for Collaboration

Topic: IPE 101

Attendees: 144

Number of teams: 34

Number of disciplines: 36

Overall Applicability Rating (Overall: The institute was applicable to our team's needs.): $96 \%$ strongly agree or agree

May 2016 IPEC Institute: Interprofessional Education:

Quality Improvement and Patient Safety

Topic: Quality Improvement and Patient Safety

Attendees: 96

Number of teams: 23

Number of disciplines: 21

Overall Applicability Rating (Overall: The institute was applicable to our team's needs.): 92\% strongly agree or agree

The Interprofessional Educational Collaborative welcomed new members to the organization (2/2/16 Press Release regarding Membership Expansion):

1. American Association of Colleges of Podiatric Medicine (AACPM)

2. American Council of Academic Physical Therapy (ACAPT)

3. American Occupational Therapy Association (AOTA)

4. American Psychological Association (APA)

5. Association of American Veterinary Medical Colleges (AAVMC)

6. Association of Schools and Colleges of Optometry (ASCO)

7. Association of Schools of Allied Health Professions (ASAHP)

8. Council on Social Work Education (CSWE)

9. Physician Assistant Education Association (PAEA) 


\section{Lawrence C. Weaver Transformative Community Service Award}

\section{Virginia Commonwealth University School of Pharmacy}

The Virginia Commonwealth University Pharmacist Collaborative Care and Outreach in the Community program forges academic-community partnerships with independent senior living facilities and underserved clinics, large-scale community outreach programs, and programs to train the next generation of health professionals.

Since it began in 2001, the PCOC program has grown to include seven formal community partnerships, with 17 full-time faculty members, more than 600 students and 37 residents providing greater than 33,000 patient care encounters around the Richmond area.

\section{Student Community Engaged Service Award}

Cedarville University School of Pharmacy

Team leader: Juanita A. Draime

Team members: Bethany G. Sibbitt, Allison E. Henry, McKenzie Shenk, Rachel Kunze Faculty advisor: Ginger Cameron, Ph.D.

Project: At Cedarville University, the Students Teaching Educational Plans for Success, or "STEPS," Initiative has allowed interprofessional student teams to provide preventative health counseling, and blood pressure, body mass index and glucose screenings, to patients at two homeless shelters. Through this program, students have seen an increase in participants reaching positive health goals, such as reducing cigarette smoking and increasing exercise.

\section{Chicago State University College of Pharmacy}

Team leader: Bernice Y. Man

Team member: Shuo T. Gao

Faculty advisor: Cindy Leslie A. Roberson, Pharm.D.

Project: The Promoting Stronger Bones Project, designed by the Student Asian Pharmacists Association at the Chicago State University College of Pharmacy, expanded access to osteoporosis screening services for underserved Asian American and Pacific Islander communities in Chicago. These services equated to approximately $\$ 30,000$ in overall savings to patients who would otherwise not have access to this type of care.

\section{Creighton University School of Pharmacy and Health Professions}

Team leader: Brian R. Dalke

Team members: Vincent J. Morris, Kendra E. Solko, Christian M. Andreen, Sarah N. Janes Faculty advisor: Ann M. Ryan Haddad, Pharm.D.

Project: The Creighton University School of Pharmacy and Health Professions developed the free Porto clinic, which has allowed interprofessional student teams to counsel more than 2,000 underserved residents since its inception in 2014. The clinic and related course focus on many of the Healthy People 2020 Leading Health Indicators related to hypertension, hyperlipidemia, and access to healthcare and prescriptions.

\section{Union University School of Pharmacy}

Team leader: Allison Todd

Team members: Cory Rossmann, Meghan Garrett, Andrea Chiles, Shelby Mills

Faculty advisor: Sean R. King, Ph.D.

Project: Union University School of Pharmacy's Project Population Health and 
Rural Medicine, or "PHaRM," evaluated the influence of functional health literacy on adherence to cholesterol, hypertension and diabetes medications within an underserved population. In order to measure adherence, students and faculty built medication profiles while performing free heart health screenings for underserved patients at various area pharmacies.

\section{Pharmacy Patient Care Process}

The Pharmacist Patient Care Process, developed and endorsed by AACP and nine other national pharmacy associations, continues to be communicated and evaluated in the pharmacy profession. Under the direction of 2015-16 Council of Faculties (COF) Chair Todd Sorensen, three COF workgroups worked on the adoption of the pharmacist patient care process in the following areas:

- AACP Policy and Programming

- Pharmacy School Curricular Adoption and Integration

- Influencing Refinement and Adoption in the Profession

The work from these groups will have multiple outcomes and impact on the academy and the profession.

\section{Pharmacy Workforce Center}

The Pharmacy Workforce Center (PWC) continues its mission to serve the pharmacy profession and the public by actively researching, analyzing, and analyzing the size, demography and activities of the pharmacy workforce. PWC supported several key workforce tools in 2015, including:

- Webinars (recordings are posted on the PWC website) discussing the 2014 National Pharmacist Workforce Survey, which is the fourth update on the demographic and work characteristics of the pharmacist workforce in the U.S.;

- The 2015 National Pharmacy Technician Workforce Study, an examination of the education, training, duties/responsibilities, level of career satisfaction, and the level of employer and profession commitment of nationally certified pharmacy technicians in the U.S.; and

- The Pharmacy Aggregate Demand Index, a national survey about pharmacy demand that is updated monthly.

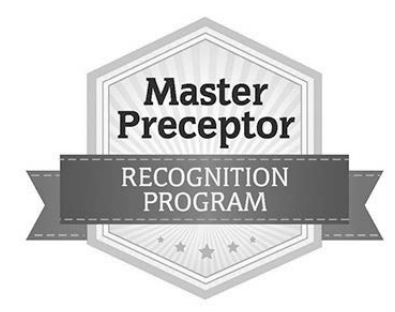

\section{Master Preceptor Recognition Program}

The Master Preceptor Recognition Program (MPRP) recognizes preceptors, who are not full-time employees of a school/college of pharmacy, for their sustained commitment to excellence in experiential education and professional Practice. 2016 was the third year of the MPRP, which had the following highlights:

- A 93\% increase in the number of applications from the initial year of the MPRP

- Funding of the program from four national pharmacy organizations (APhA, ASHP, NABP Foundation and NACDS Foundation)

- Selection of seven awardees from 7 of the $8 \mathrm{NABP} / \mathrm{AACP}$ districts 


\section{IOM Pharmacy Fellowship/ \\ National Academy of Medicine}

\section{IOM Pharmacy Fellowship}

The profession was fortunate to have two pharmacists engaged as Anniversary Fellows in Pharmacy at the Institute of Medicine (IOM) beginning in October 2014. Steven Smith, University of Florida, and Jennifer Christian, Quintiles, were each profiled in Academic Pharmacy Now during their 2-year fellowship experience. In 2015 the members of the IOM deliberated on a proposal for a restructuring and renaming of their organization. The result was in October 2015 that the IOM became the National Academy of Medicine (NAM) within the National Academies of Science, Engineering and Medicine organizational structure.

As this year draws to a close the selection process for the 2016-18 NAM Anniversary Fellow in Pharmacy was nearing completion. The new fellow will be announced during the 2016 AACP annual meeting.

\section{National Academy of Medicine Global Forum workshop} Global Forum on Innovation in Health Professional Education (Global Forum) Workshop: The Role of Accreditation in Enhancing Quality and Innovation in Health Professions Education

April 21-22, 2016

Workshop Overview: The workshop concerned the role of accreditation to advance quality and innovation for interprofessional education across the health professions. The outcome of the workshop was the proposed need to build a competency-based accreditation system across health professions which balances global standards with local relevance.

The Global Forum also published a consensus report, A Framework for Educating Health Professionals to Address the Social Determinants of Health, in Spring 2016. 


\section{Critical Issue 4 Advocacy}

How do we strategically position AACP to carry out its advocacy agenda to build recognition of our members' contributions to the health of the public?

\section{Advocacy Update}

With the second session of the 114th Congress moving toward conclusion and a new administration on the horizon, AACP focused its advocacy on demonstrating the alignment of the teaching, research and service activities at our member institutions with important public policy discussions and initiatives. These public policy discussions and initiatives include:

- Speeding biomedical innovation to patients in need of cures;

- Reducing the negative consequences of opioid drug use and the alarming increase in heroin use; and

- Continued action to help users of tobacco products quit and to ensure that non-users never start.

AACP met with and shared information with congressional, White House and agency staff responsible for initiatives including:

- 21st Century Cures Act (HR 2);

- Vice President Biden's Cancer Moonshot initiative;

- President Obama's opioid abuse and heroin use initiative; and

- The Center for Disease Control and Prevention's TIPS campaign

- Pharmacist Provider Status

Information shared included:

- Three new issue briefs describing our engagement in and commitment to innovation, professional and graduate education and interprofessional education;

- Research statistics related to cancer research gathered through our Faculty Research Grants Database;

- Statement of commitment that our members would be or already are "educating every student to be ready to provide, according to state law, life-saving interventions to patients and individuals who may encounter those at risk of overdose from opioid use and counsel them on appropriate use of these life-saving interventions;" and

- A report, Getting to zero: The role of academic and professional pharmacy in tobacco cessation, describing the teaching, research and service tobacco cessation activities at our member institutions. 


\section{Script Your Future}

AACP is proud to continue its support for the fourth continuous year for the 2015

SCRIPT YOUR FUTURE
National Consumers League (NCL) Script Your Future Medication Adherence

Team Challenge for health professions students, with the following schools being recognized at the 2015 AACP Annual Meeting for their innovation, commitment and creativity:

\author{
University of Pittsburgh School of Pharmacy \\ National Challenge Award \\ Creative Inter-Professional Team Event Award \\ University of Maryland School of Pharmacy \\ National Challenge Award \\ University of Charleston School of Pharmacy \\ Health Disparities, Under-Represented Community Outreach Award \\ Northeast Ohio Medical University College of Pharmacy \\ Communication and Media Outreach Award
}




\section{Critical Issue 5 Research and Scholarship}

How do we impact academic pharmacy's ability to strengthen research and other scholarship in practice, education and the pharmaceutical, administrative, translational and clinical sciences?

\section{AACP Awards}

2015 Robert K. Chalmers Distinguished Pharmacy Educator Award:

John E. Murphy, Pharm.D., interim dean, professor and associate dean of Academic Affairs \& Assessment at The University of Arizona, was recognized for his outstanding achievements as an educator and mentor, his innovations in the classroom, and his overall impact on pharmacy education and the profession.

2015 Paul R. Dawson Biotechnology Award:

Marie Chisholm-Burns, Pharm.D., M.P.H., dean of The University of Tennessee, was honored for her exceptional contributions to teaching and scholarship that have positively impacted the quality of patient outcomes.

2015 Volwiler Research Achievement Award:

Kuo-Hsiung Lee, Ph.D., Kenan Distinguished Professor and director of Natural Products Research Laboratories at the University of North Carolina at Chapel Hill, was recognized for his record of sustained excellence in research in a given area of the pharmaceutical and clinical sciences, pharmacy practice and the social and administrative sciences, and for outstanding contributions to the respective disciplines.

\section{New Investigator Awards Program}

The New Investigators Award (NIA) Program has reached the 30 th year of providing junior faculty their first externally funded research award. In partnership with the Council of Sections

Highlights from this year include:

- Review of 119 applications by the Council of Sections

- Awards were provided to 14 recipients

- Research approaches ranging from single cell function and drug discovery to analysis of workflow impact on medication errors.

ACADEMIC RESEARCH FELLOWS PROGRAM leading and advancing team science

\section{Academic Research Fellows Program}

AACP continued to provide innovative training for building research leadership in the academic pharmacy community with established faculty participating in the 2015-2016 Academic Research Fellows Program (ARFP):

- 10 ARFP Fellows from diverse colleges and schools participated

- Goals of deepening faculty knowledge, research networks and leadership skills were met with the assistance of Master Mentors

- ARFP Fellows received training in research advocacy

\section{Pharmacy Faculty Research Grant Data}

AACP conducted the annual analysis of extramural research funding conducted for FY15 and demonstrated continued growth and success in the academic pharmacy research community. The level of activity in research and training activities speak to the dedication of students, postdocs, clinical fellows, staff, faculty and admin- 
istrators-as pharmacy schools lead the way for innovation and creation of new knowledge that will improve the nation's health.

- Highest number of pharmacy schools receiving extramural research awards (100)

- Overall, a 4\% increase in research funding from the National Institutes of Health

- Highest level of extramural research awards received totaling \$552,518,233

\section{Innovation in Graduate and Postdoctoral Education}

The AACP Research and Graduate Education Committee (RGAC) examined the accessibility, affordability and accountability of graduate programs and postdoctoral training, both basic and clinical, the schools and colleges of pharmacy. Activities focused on creating and sustaining the impact of innovative and high quality graduate education programs.

- Focus groups and a national survey were conducted regarding graduate education

- Consideration of competencies and assessment practices, development of student pipelines, engagement of underrepresented minorities, understand emerging and non-tradition career options, forecasting the research-based workforce for academic pharmacy.

\section{Advocacy for Pharmacy Research and Graduate Education}

A high priority for AACP has been creating enhanced awareness and visibility for the research and educational efforts of the academic pharmacy research community at local, state and federal levels

- Meetings with leaders of funding agencies, including the NIH, FDA, NSF, AHRQ and other funding sources were conducted with AACP staff

- AACP staff provided engagement provided representation at the Council of Graduate School, the AAMC Graduate Education and Training Committee, Precision Medicine Initiative Policy Discussions, Critical Path CAMD, and AAAS Affiliates among other annual meetings.

- AACP staff and volunteers provided outreach on pharmacy careers to over 350,000 elementary, middle school, high school students and their parents at the 2016 US Science and Engineering Fair.

\section{Knowledge Management}

AACP continues its commitment to adopt and implement the philosophy and practices of knowledge management. Several initiatives began in 2015 and will continue as our knowledge management framework and strategy evolves, including:

- AACP Twitter chats

- The Secretary of Knowledge Management leadership position for councils, sections and SIGs

- Avenues for members to communicate and network beyond AACP meetings and institutes

- Interprofessional Education Community of Practice pilot to create a network for knowledge transfer and accumulation

AACP Connect, our online platform that will facilitate sharing, searching and retrieving knowledge and content through discussion boards, will be launched to the full AACP membership 4th quarter 2016. 
Activity and statistics for the American Journal of Pharmaceutical Education (AJPE) for 2015 (Vol.79)

- 10 issues were published in electronic, open access format; a print edition was produced and sent to member institutions and paid subscribers.

- Journal Transitions:

- The editorial office welcomed James Peak as its new editorial assistant, who works out of the University of New England office with AJPE Editor Dr. Gayle Brazeau.

- Dr. Nancy Fjortoft of Midwestern University Chicago and Dr. Lauren Schlesselman of University of Connecticut joined Drs. Adam Persky, Frank Romanelli and Claire Anderson as associate editors.

- Editorial Board of Directors:

- New members: Patricia Darbishire (Purdue University), Karl Hess (Western University of Health Sciences), Daniel Kennedy (Western New England University), Jennifer Mathews (St. John Fisher College), and Bernie Olin (Auburn University) -3-year terms; Reappointments: Zubin Austin (University of Toronto), Sudip Das (Butler University), Gary Delander (Oregon State University), JoLaine Draugalis (The University of Oklahoma), Patrick Hardigan (Nova Southeastern University), and Therese Poirier (Southern Illinois University-Edwardsville)-3-year terms.

- Rufus A. Lyman Award Winner:

- "Towards an Operational Definition of Clinical Competency in Pharmacy," by L. Douglas Ried, PhD, (University of Texas at Tyler) and Charles A. Douglas, PhD, MBA, (Texas A\&M Health Science Center)

\section{Journal Activity in 2015 (Volume 79)}

Manuscripts submitted: $\mathbf{5 2 9}$

Manuscript acceptance rate: $35 \%$

Number of Reviewers: $\mathbf{5 2 8}$

Manuscripts Published:

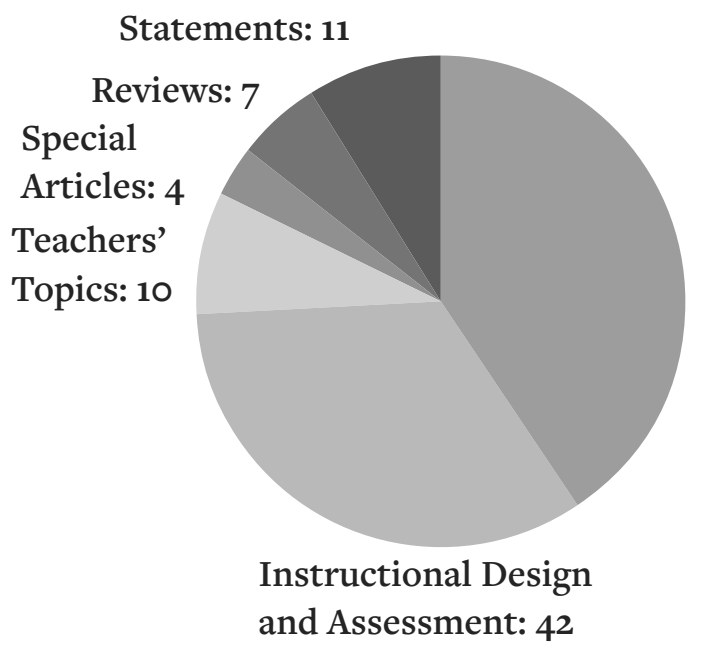

and Assessment: 42
Research: $\mathbf{5 1}$

\section{Other Materials \\ Published: \\ Viewpoints: 19 \\ Addresses: 4}

Reports and Minutes: 21

Letters: 14 


\section{Critical Issue 6 AACP Financial Resources and Infrastructure}

How do we ensure that the organization has the financial resources shortterm (one to three years) and long-term and the necessary infrastructure to support the mission and vision?

\section{Staffing}

By year-end, there were 32 full-time AACP staff members and three individuals working on a part time basis, including our Human Resources consultant. During this year decisions resulted in the transition of our Sewell Fellow into a full-time staff position to pursue development of a robust knowledge management model that better enables AACP to deploy the information assets of the association and our members. AACP also reinstated a staff position overseeing Information Technology which had been contracted externally for approximately one year.

\section{Treasurer's Report}

With a $\$ 13$ million budget, AACP continues to maintain a stable financial position. As of April 30, 2016, assets total nearly $\$ 9.7$ million; two thirds of which are comprised of cash and investments. While institutional membership growth and the success of PharmCAS have contributed to the Association's financial strength over the years, AACP has experienced increased financial risk as these revenue streams have begun to level off. In the fiscal year that will end in June, AACP is projecting a net operating loss of $(\$ 400 \mathrm{~K})$. This is despite the fact that membership remains robust and key programs like the Annual Meeting, Interim Meeting and the Institutes have maintained a high level of attendance.

Student affairs revenues now account for 47 percent of total revenue, down from 55 percent in 2011. Since its inception in 2002 PharmCAS has been the engine for growth in AACP, providing funding for the development of many programs across the Academy, including but not limited to curricular quality, faculty recruitment and retention, and advocacy efforts. The natural maturing of these services and the erosion of corporate and industry support means AACP must rely more heavily on member-generated fees to sustain the current level of member services, as well introduce new programs-especially for those colleges and schools that cannot cost-effectively develop them on their own

In an effort to diversify revenue streams, the AACP Board approved the opportunity to develop and market the first online multi player learning tool focused on the core competencies for Interprofessional Education and Practice with the formation of Professions Quest LLC in February 2014. Due to the delay in maturation of sales, this $\$ 1.5$ million venture will be in a dormant state during FY2017 until a viable business option is identified as quickly as possible.

AACP embarked on a new strategic planning project this year to strategically align the plans of the Board of Directors, Councils, Sections and staff. The new strategic planning process have given us the opportunity to assess prospects for new revenue resources. It has also given us the chance to begin to assess whether our infrastructure is right-sized for what lies ahead. What does the current financial picture tell us about the future of the Academy? For sure, AACP must rebalance its revenue streams to reduce dependence upon student driven fees and programs. First, there is a pro- 
posal to initiate a tiered institutional dues increase starting in FY2017. Second, AACP remains sensitive to institutional member budgets and is extremely responsive to member needs as new services are launched, which help schools "achieve more with less". With innovative member programs and initiatives under development, your Association is well poised to continue meeting member needs as effectively as ever.

Financials, 2013-2015

\begin{tabular}{|c|c|c|c|}
\hline units in $\$$ and 000s & 2013 & 2014 & 2015 \\
\hline Cash & $\$ 2,055$ & $\$ 2,238$ & $\$ 812$ \\
\hline Receivables & 351 & 173 & 90 \\
\hline Investments & 6,106 & 7,015 & 7,288 \\
\hline Fixed Assets & 736 & 631 & 795 \\
\hline Other & 848 & 900 & 1,262 \\
\hline Assets & 10,096 & 10,957 & 10,247 \\
\hline Accounts Payable & 772 & 810 & 717 \\
\hline Dues received in advance & 2,217 & 2,306 & 2,601 \\
\hline Advance registration and exhibit fees & 1,884 & 1,1667 & 1,517 \\
\hline Note payable & 63 & 51 & 38 \\
\hline Liabilities & 4,936 & 4,834 & 4,873 \\
\hline Unrestricted net assets & 4,813 & 5,663 & 4,905 \\
\hline Temporarily restricted net assets & 83 & 194 & 203 \\
\hline Permanently restricted net assets & 264 & 266 & 266 \\
\hline Net Assets & 5,160 & 6,123 & 5,374 \\
\hline Liabilities and Net Assets & $\$ 10,096$ & $\$ 10,957$ & $\$ 10,247$ \\
\hline Support \& Revenue & 2013 & 2014 & 2015 \\
\hline Membership dues & 3,478 & 3,542 & 3,774 \\
\hline Grants and contracts & 239 & 260 & 214 \\
\hline Meeting registrations and other fees & 2,169 & 2,158 & 2,205 \\
\hline PharmCAS application fees & 5,858 & 6,096 & 5,673 \\
\hline Sales and royalties & 862 & 810 & 818 \\
\hline Other income & 198 & 124 & 60 \\
\hline Total Support \& Revenue & 12,804 & 12,990 & 12,744 \\
\hline \multicolumn{4}{|l|}{ Expenses } \\
\hline \multicolumn{4}{|l|}{ Program Services } \\
\hline Individual member services & 1,042 & 1,013 & 1,068 \\
\hline Meetings & 2,655 & 2,559 & 2,816 \\
\hline PharmCAS & 4,622 & 4,883 & 4,735 \\
\hline Other programs & 2,021 & 2,358 & 2,480 \\
\hline \multicolumn{4}{|l|}{ Support Services } \\
\hline Office administration & 2,466 & 2,238 & 2,394 \\
\hline Total Expenses & 12,806 & 13,051 & 13,493 \\
\hline Increase (Decrease) in Operations & (2) & $(61)$ & $(749)$ \\
\hline Investment income, gains and losses & 537 & 914 & 1 \\
\hline Increase (decrease) in Net Assets & $\$ 535$ & $\$ 853$ & $\$(748)$ \\
\hline
\end{tabular}

